\title{
SOSIALISASI DAN PELATIHAN PENGGUNAAN MESIN CETAK DIGITAL PRINTING SEBAGAI PENUNJANG KETERAMPILAN HARD SKILL BAGI SISWA SMK PERGURUAN LAKSAMANA MARTADINATA MEDAN
}

\author{
Juwairiah $^{1^{*}, \text { Meisi Riana }}{ }^{2}$, \\ Teknik Grafika, POLITEKNIK NEGERI MEDIA KREATIF, Indonesia \\ juwairiah@polimedia.ac.id, meisi_riana@polimedia.ac.id
}

\begin{abstract}
ABSTRAK
Abstrak: Pelatihan dalam rangka kegiatan Pengabdian Pada Masyarakat ini bertujuan untuk memberikan bekal ilmu pengetahuan dan teknologi tentang bagaimana menggunakan mesin cetak digital printing. Mesin cetak yang digunakan adalah mesin cetak digital printing Fuji Xerox produksi Jepang. Peserta pelatihan merupakan siswa SMK Perguruan Laksamana Martadinata Medan. Pelaksanaan diawali dengan memberi materi sampai ke proses cetak . Materi diakhiri dengan memberikan tugas bagi masingmasing peserta untuk mencetak brosur secara mandiri. Dikarenakan PPKM darurat 4 di Kota Medan maka pihak sekolah hanya mengizinkan 5 orang siswa untuk mengikuti pelatihan tersebut. Dari peserta dengan jumlah 5 orang siswa, semuanya dapat mengikuti pelatihan dari awal sampai akhir yaitu dapat menyelesaikan tugas mandiri dengan baik, mampu mencetak brosur yang berkualitas. Metode yang digunakan dalam pelatihan ini antara lain metode demonstrasi yaitu peserta secara langsung praktek sesuai dengan keadaan yang sebenarnya mencetak brosur menggunakan mesin digital printing, program yang digunakan yaitu program Fiery 1,. Metode evaluasi dengan melihat perbedaan kualitas cetakan sebelum dan sesudah pelatihan. Hasilnya berupa keterampilan hardskill mencetak brosur dengan mesin digital printing yang sesuai dengan standar cetak brosur yaitu hasil cetak yang presisi.
\end{abstract}

Kata Kunci: digital printing; brosur; hard skill

Abstract: This training in the context of Community Service activities aims to provide knowledge and technology on how to use digital printing machines. The printing machine used is a Fuji Xerox digital printing machine produced by Japan. The participants of the training were students of SMK Laksamana Martadinata Medan. Implementation begins with giving the material to the printing process. The material ended by giving each participant an assignment to print a brochure independently. Due to emergency PPKM 4 in Medan City, the school only allowed 5 students to attend the training. Of the participants with a total of 5 students, all of them were able to take part in the training from start to finish, namely being able to complete independent assignments well, being able to print quality brochures. The methods used in this training include the demonstration method, where participants directly practice according to the actual situation of printing brochures using a digital printing machine, the program used is the Fiery 1 program. Evaluation method by looking at the difference in print quality before and after training. The result is hard skills in printing brochures with a digital printing machine that complies with brochure printing standards, namely precise printing results.

Keywords: digital printing; brochure; hard skills

\section{A. LATAR BELAKANG}

Digital printing merupakan teknologi cetak modern pada saat ini untuk mencetak gambar/citra digital yang diolah oleh komputer ke permukaan material atau media fisik 
oleh mesin cetak (printer). Pada umumnya, proses ini digunakan untuk pekerjaan percetakan dengan volume atau jumlah terbatas. Dengan teknologi digital printing, beragam kebutuhan cetak dapat diselesaikan dengan cepat dan akurat. Digital printing tidak hanya dihubungkan dengan industri percetakan dengan volume besar, tapi juga dapat juga berkaitan dengan industri promosi atau periklanan untuk di dalam ruangan (indoor) dan luar ruangan (outdoor) (Saharja, 2020). SMK sebagai sekolah yang menyelenggarakan pendidikan kejuruan yang menerapkan program keahlian seperti teknik mesin, perkantoran, seni rupa, tata boga, administrasi dll mempunyai peran penting memberi bekal salah satunya hard skill yang menunjang profesional skill seperti memahami penggunaan komputer. Hard skill merupakan ketrampilan teknis dalam bidang ilmu pengetahuan dan teknologi yang diperoleh dari otodidak, bangku sekolah, kuliah, pelatihan (Petro \& Swatan, 2019).

Era multi tasking seperti saat ini diperlukan kecepatan, dan ketepatan dalam menyelesaikan proses produksinya. Ditandai dengan perubahan lingkungan yang cepat, secepat perubahan teknologi informasi. Hal ini menuntut kepekaan perusahaan bisnis industri agar tetap bertahan di tengah- tengah perubahan lingkungan ini (Wasesa \& Jumali, 2020). Teknologi memiliki dampak positif maupun dampak negatif, tergantung bagaimana cara memanfaatkan teknologi tersebut. Siswa menjadi generasi penerus bagi bangsa dan negara harus mempunyai pengetahuan bagaimana dalam memanfaatkan teknologi dengan baik (Guntoro et al., 2019).

Berkembangnya persaingan teknologi pada era globalisasi, menuntut industri percetakan untuk dapat memperoleh informasi pemeliharaan secara tepat, cepat dan relevan. Untuk mendapatkan informasi tersebut, tentunya harus menggunakan teknologi informasi. Saat ini banyak perusahaan percetakan yang sedang berkompetisi untuk memberikan pelayanan pemeliharaan yang optimal melalui penggunaan dan pengembangan teknologi informasi dalam segala bidang (Septiara et al., 2020)

Kemunculan teknologi digital membuka peluang di berbagai bidang industri. Teknologi komputer dan printer yang ada sekarang telah memungkinkan kita untuk mencetak tidak hanya teks dan gambar sederhana, namun sudah dapat mencetak dengan hasil kualitas foto (Yuniarti \& Mauliana, 2012)

Semakin meningkatnya kebutuhan akan produktivitas dalam penggunaan mesin percetakan dan fasilitas pendukungnya, maka kebutuhan akan fungsi pemeliharaan akan semakin bertambah besar. Perkembangan ini menimbulkantantangan bagi CV. Wujud Unggul, sebagaisuplier percetakan berskala nasional,untuk dapat memenuhi kebutuhan fungsi pemeliharaan dengan cara meningkatkankemampuan pemeliharaan dalam perawatan dan perbaikan mesin.CV (Septiara et al., 2020)

Bila dikaji secara mendalam inti dari tujuan pendidikan, maka prinsipnya adalah mengembangkan tiga aspek utama yaitu aspek peng- etahuan, aspek sikap, dan aspek keterampilan. Dalam dunia pendidikan, bila dihubungkan dengan tuntunan lapangan kerja selalu menjadi masalah yang kompleks, sebab di satu sisi pendidikan itu berjalan menurut dinamikanya, sementara lapa- ngan kerja menghendaki perubahan maupun keterampilan (Wahid \& Luhriyani, 2015)

Di Indonesia sendiri, industri penerbitan tumbuh menjadi $14,9 \%$ diikuti dengan dengan pertum- buhan industri packaging yang naik 13,2\% dan industri periklanan 12,1\% (Margomo, 2018). Menurut narasumber satu (wawancara pribadi, 14 Maret 2018), pendiri perusahaan digital printing banyaknya universitas, lembaga pendidikan dan perkantoran di Kota Malang memiliki permintaan akan kebutuhan percetakan, banyak pengusaha 
yang tidak mesin printing hanya berperan sebagai perantara untuk memnuhi pesanan konsumen (Margomo, 2018). Digital printing kini sedang menjadi trend khususnya untuk kepentingan promosi perusahaan. Disamping itu permintaan akan produk digital printing semakin meningkat seiring dengan banyaknya bermunculan Perusahaan Digital Printing baru. Persaingan akan semakin sengit karena teknologi pendukung pasar digital printing terbuka untuk dikuasai dan diimplementasikan (Yuniarti \& Mauliana, 2012)

Pengabdian ini bertujuan untuk memberikan pembelajaran serta memberikan edukasi bagi siswa-siswi SMK Perguruan Laksamana Martadinata Medan dalam memanfaatkan internet secara sehat dan aman. Adapun manfaat dari pengabdian tersebut adalah memberikan wawasan tetang pentingnya internet untuk pendidikan yang dapat digunakan sebagai media pembelajaran dan mampu menggunakan dengan bijak dan optimal . Kegiatan PKM ini diharapkan siswa-siswi SMK Perguruan Laksamana Martadinata Medan dapat keterampilan mengoperasikan aplikasi komputer dengan baik dan untuk mengetahui seberapa jauh kemampuan para siswa dalam mengoperasikan mesin digital printing sehingga akan memberikan manfaat bagi mereka sebagai bekal dalam kesiapan mereka ketika masuk dunia kerja maupun perguruan tinggi yang membutuhkan ketrampilan.

Kegiatan PKM ini diharapkan siswa-siswi SMK Perguruan Laksamana Martadinata Medan dapat ketrampilan mengoperasikan mesin digital printing dengan baik dan untuk mengetahui seberapa jauh kemampuan para siswa dalam mengoperasikan Microsoft Excel sehingga akan memberikan manfaat bagi mereka sebagai bekal dalam kesiapan mereka ketika masuk dunia kerja maupun perguruan tinggi yang membutuhkan ketrampilan dalam aplikasi komputer.

\section{B. METODE PELAKSANAAN}

Program PKM ini menggunakan metode pendekatan pelatihan sehari yang dijadwalkan secara efisien dan padat, namun tetap berlangsung nyaman dan kondusif agar peserta dapat mengekplorasi aktivitas kreatifnya dengan baik (Witari \& Suryana, 2020)

Kegiatan dilakukan di Laboratorium Digital Printing Politeknik Negeri Media Kreatif PSDKU Medan, pada hari Sabtu, 23 Agustus 2021, dari jam 10.00 - 16.00 WIB. Tujuan utama dari pelatihan ini adalah membekali peserta untuk terampil menggunakan mesin cetak digital printing.

Metode yang digunakan selama proses pelaksanaan kegiatan pengabdian kepada masyarakat meliputi: (1) metode demonstrasi dilakukan untuk materi latihan dan penugasan, ketika siswa memasuki tahap proses penggarapan (praktik). Metode ini dilakukan mulai dari awal sampai akhir, berurutan secara teknis, sampai siswa- siswi benar-benar menguasai keterampilan ini dengan baik (Ditto, 2017) (2) metode ceramah untuk memberikan penjelasan langsung tentang menggunakan mesin cetak digital printing, (3) metode diskusi untuk curah pendapat antara peserta dengan tim pengabdian pada hal-hal yang dianggap sulit, (4) metode praktek untuk memberikan kesempatan kepada peserta mempraktekan cara cetak menggunakan mesin digital printing

\section{HASIL DAN PEMBAHASAN}


Juwairiah, Sosialisasi Dan Pelatihan...

Langkah Kegiatan Adapun langkah yang dilakukan pada kegiatan pengabdian masyarakat yang dilaksanakan di Laboratorium Politeknik Negeri Media Kreatif PSDKU Medan yaitu :

1. Memberikan materi dan arahan cara menggunakan mesin digital printing.

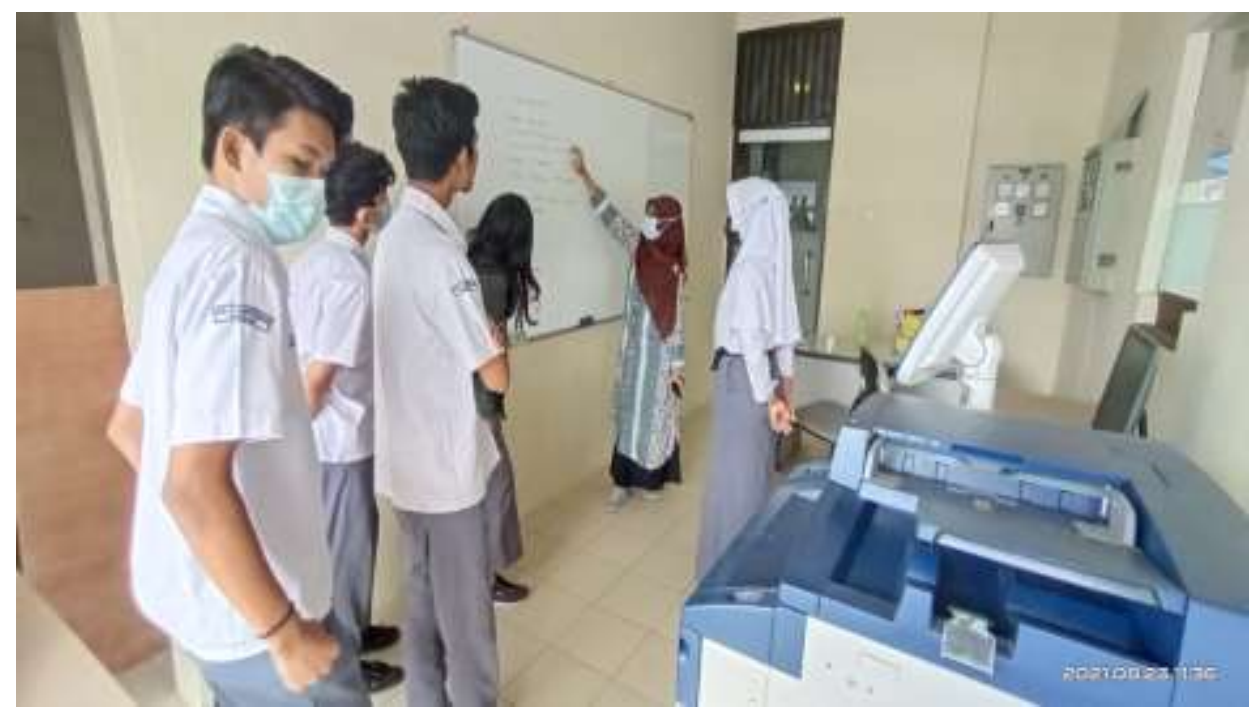

2. Menghidupkan Mesin Digital Printing : dengan menekan power supply, tekan tombol pada bagian dalam mesin (on/off), tekan tombol pada bagian luar $\operatorname{mesin}(\mathrm{On} / \mathrm{Off})$

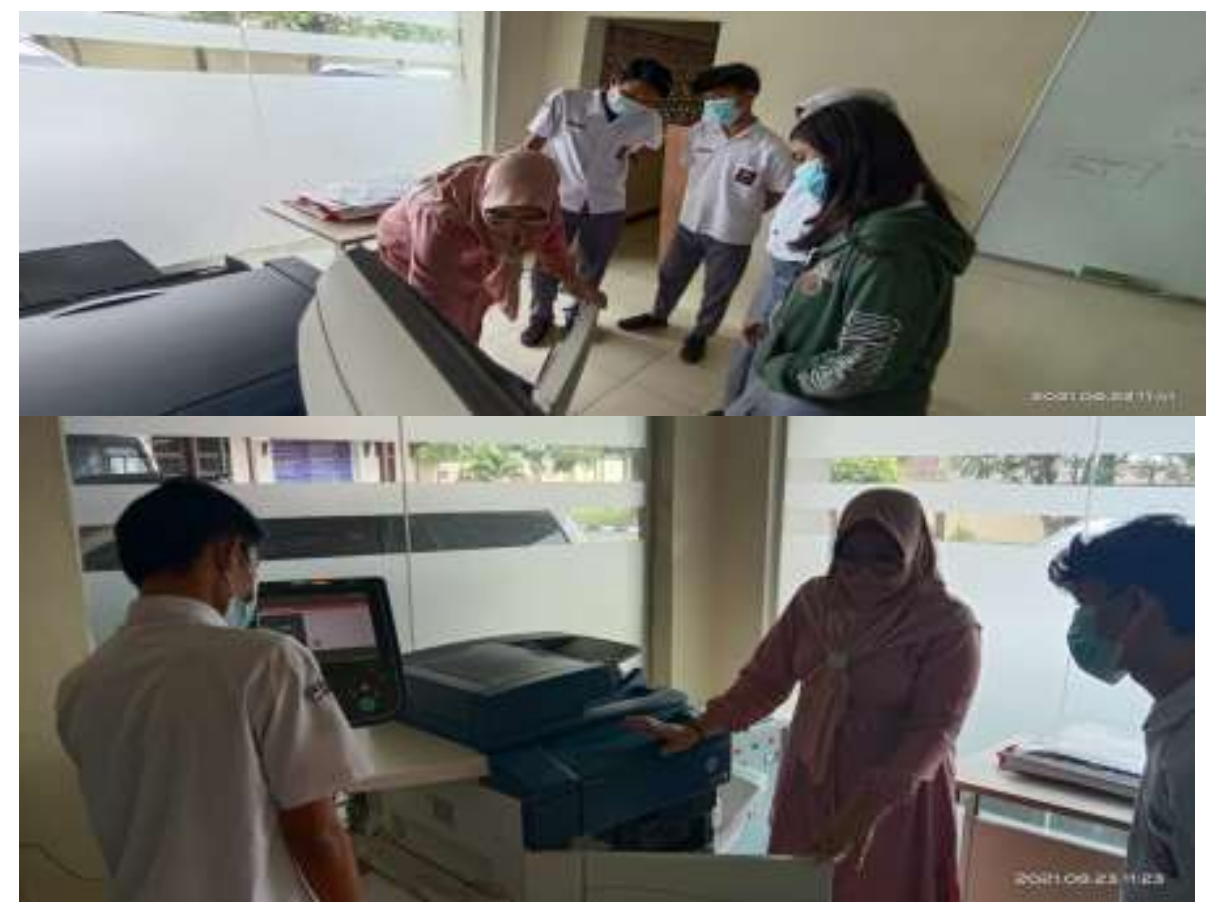

Gambar 1. Proses Menghidupkan Mesin Digital Printing 
3. Hidupkan PC/Komputer : Buka aplikasi Fiery 1

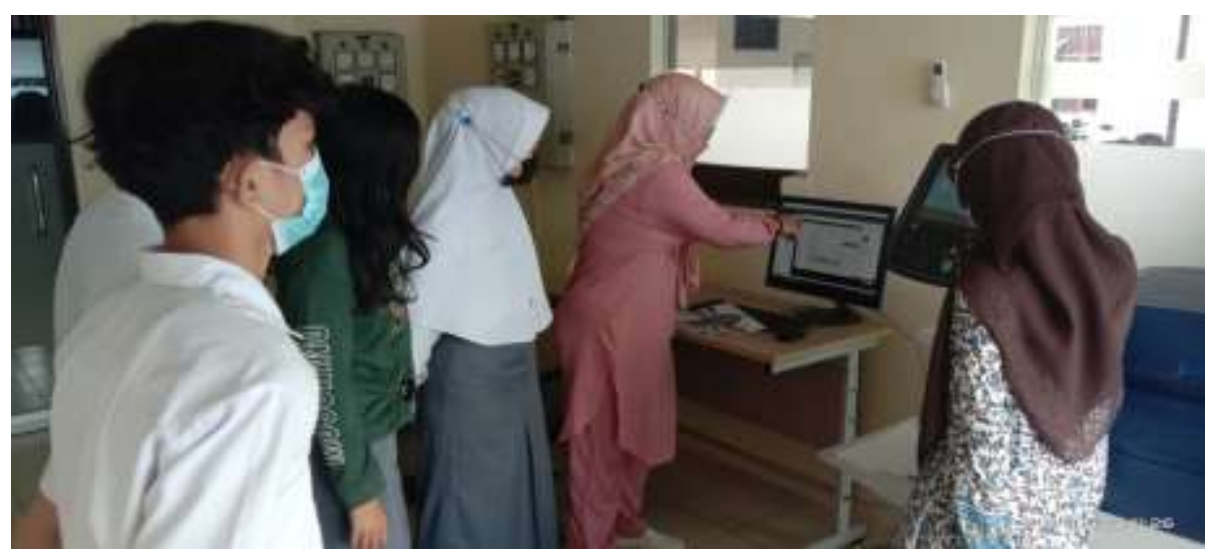

Gambar 2 . Prose Menghidupkan Aplikasi Fiery 1

4. Pada aplikasi Fiery 1 pilih Job Centre drag file "pdf" ke Held, sebelum di print, cek properties dengan klik kanan di file "pdf”. Pada properties berkaitan dengan mesin dan pengatura dimonitor yang diperikas adalah bagian :

Quick Access : Perhatikan jumlah copy dan paper size

Media : Perhatikan Paper Catalog pilih sesuai dengan nama file yang akan di print agar tidak eror di monitor

Finishing : Perhatikan Output Delivery "Face Down dan Face Up"

Face Down : Jalan kertas dari bawah naik ke atas, hasil posisi cetakan berada di bawah. Face down ini sering terjadi masalah karena kertas sering terjepit ata nyangkut di dalam mesin.

Face Up : Jalan kertas lurus normal, hasil cetakan di atas. Face up ini biasa dipakai karena kertas terjepit atau nyangkut itu resikonya kecil.

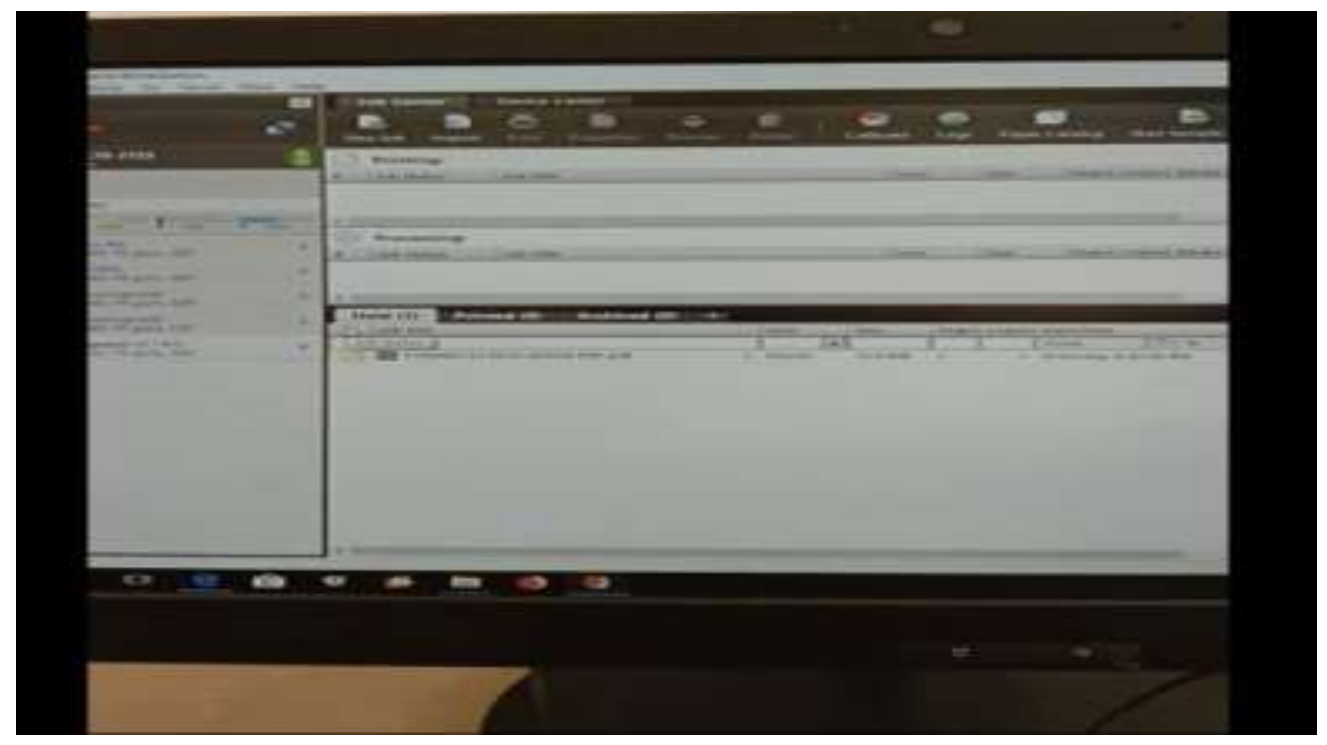

Gambar 3. Job Centre Pada aplikasi Fiery 1 


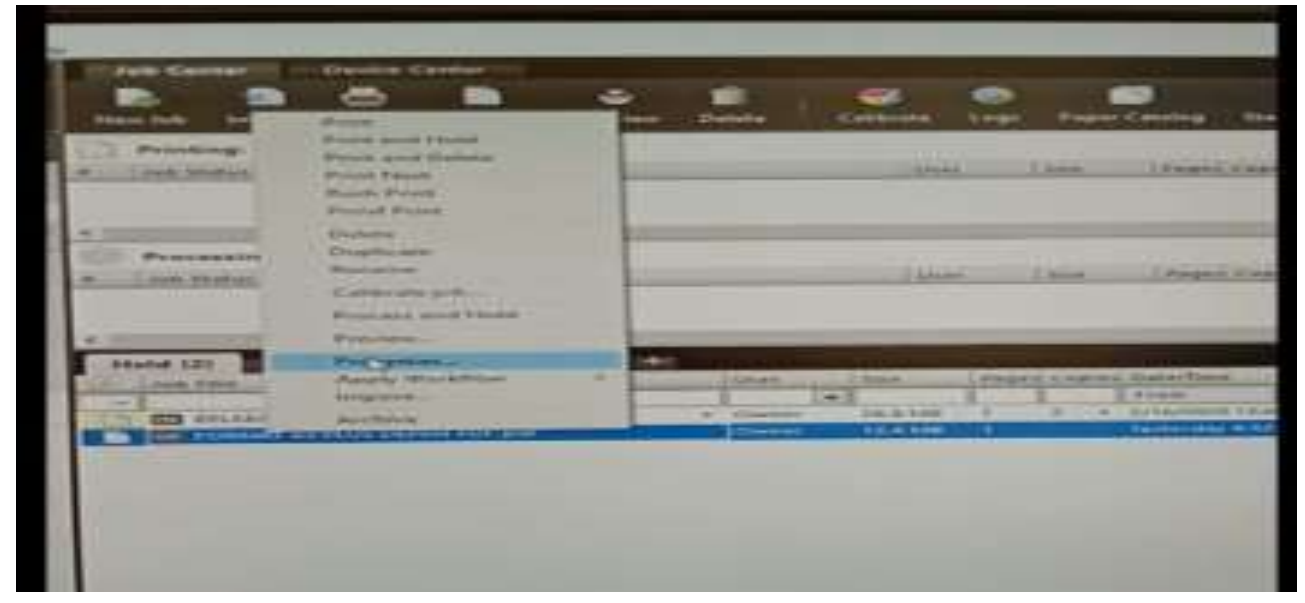

Gambar 4. ". Properties berkaitan dengan mesin dan pengatura dimonitor

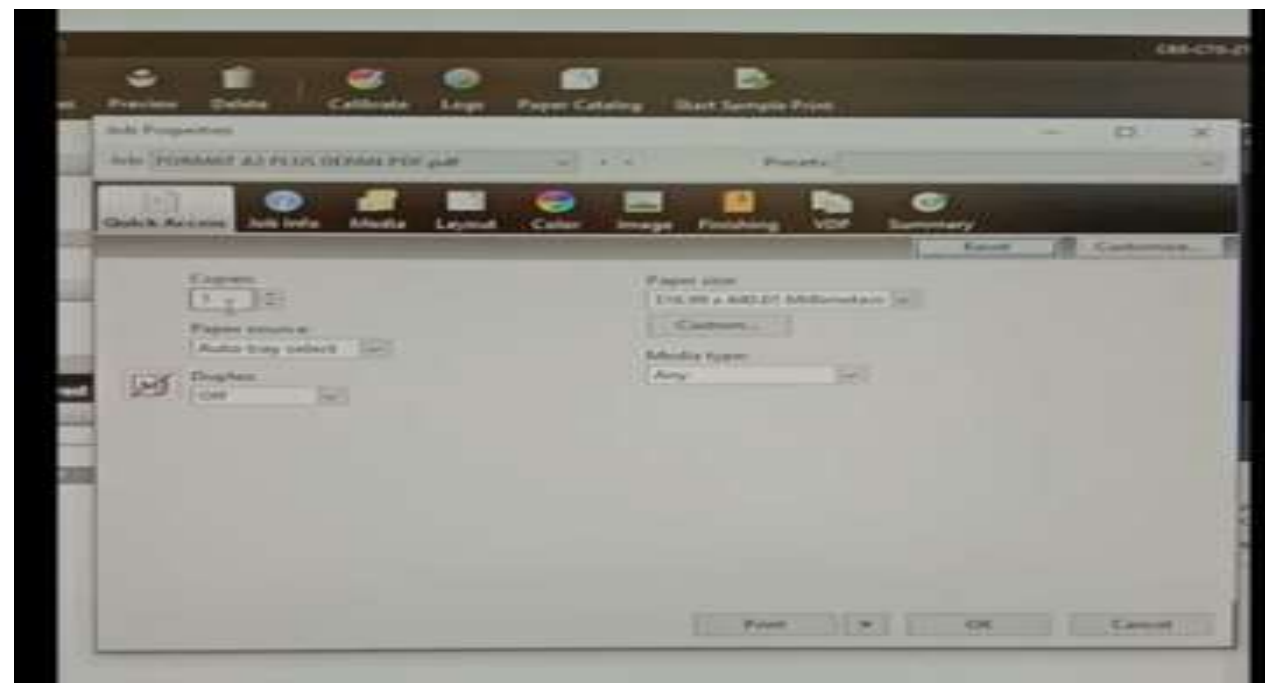

Gambar 5. Quick Access Menentukan Jumlah Copy dan Paper Size

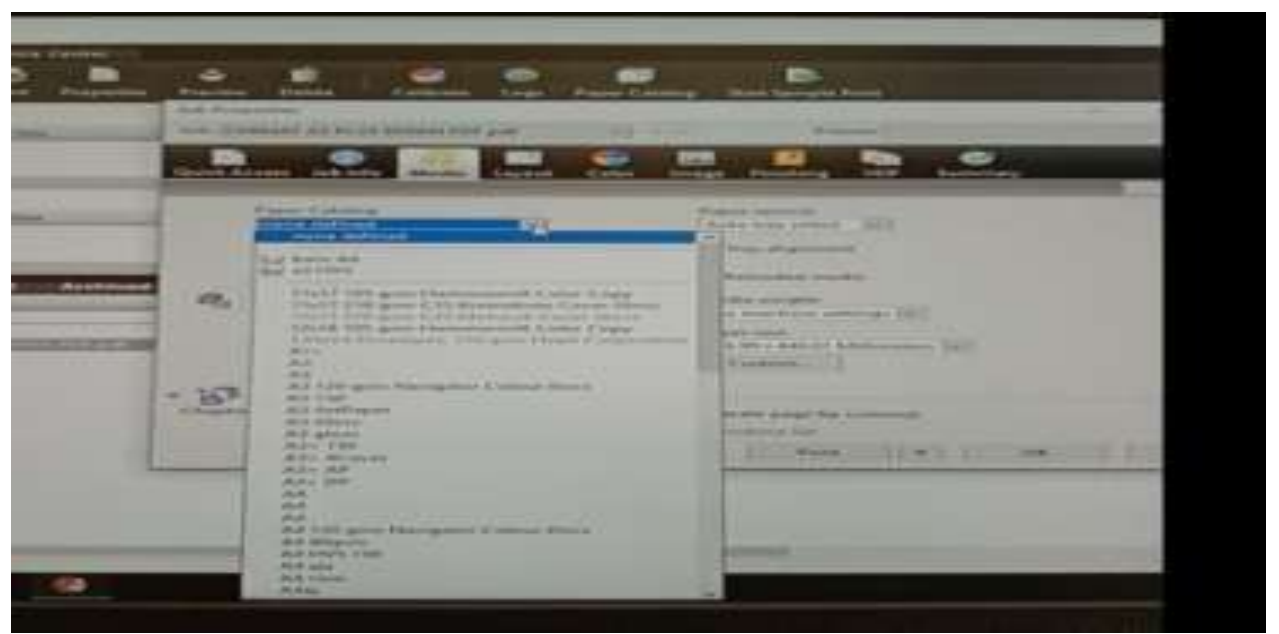

Gambar 6. Media : Pilihan Paper Catalog 


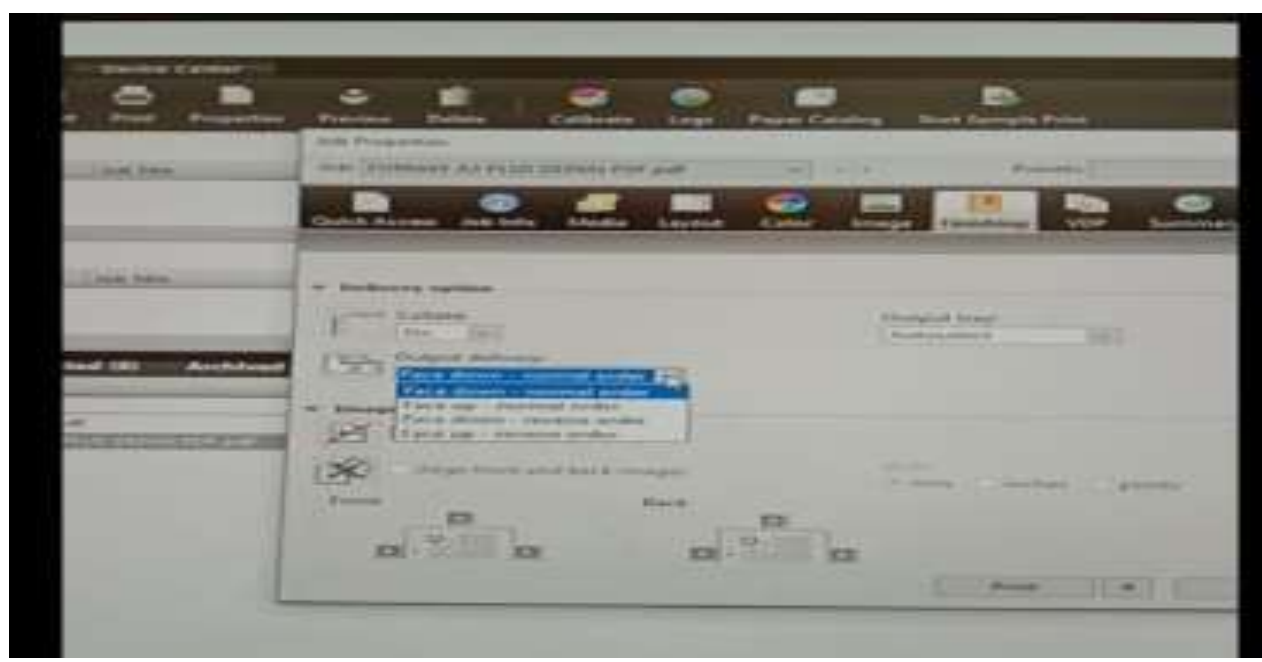

Gambar 7. Finishing : Output Delivery "Face Down dan Face Up"

5. Layar Monitor Mesin. Perhatikan bagian Set Up : pilih Paper Atributes untuk mengatur kertas, pilih tray sesuai temoat dimana kertas diletakkan.

6. Kemudian pilih Print di aplikasi Fiery 1 untuk mencetak.

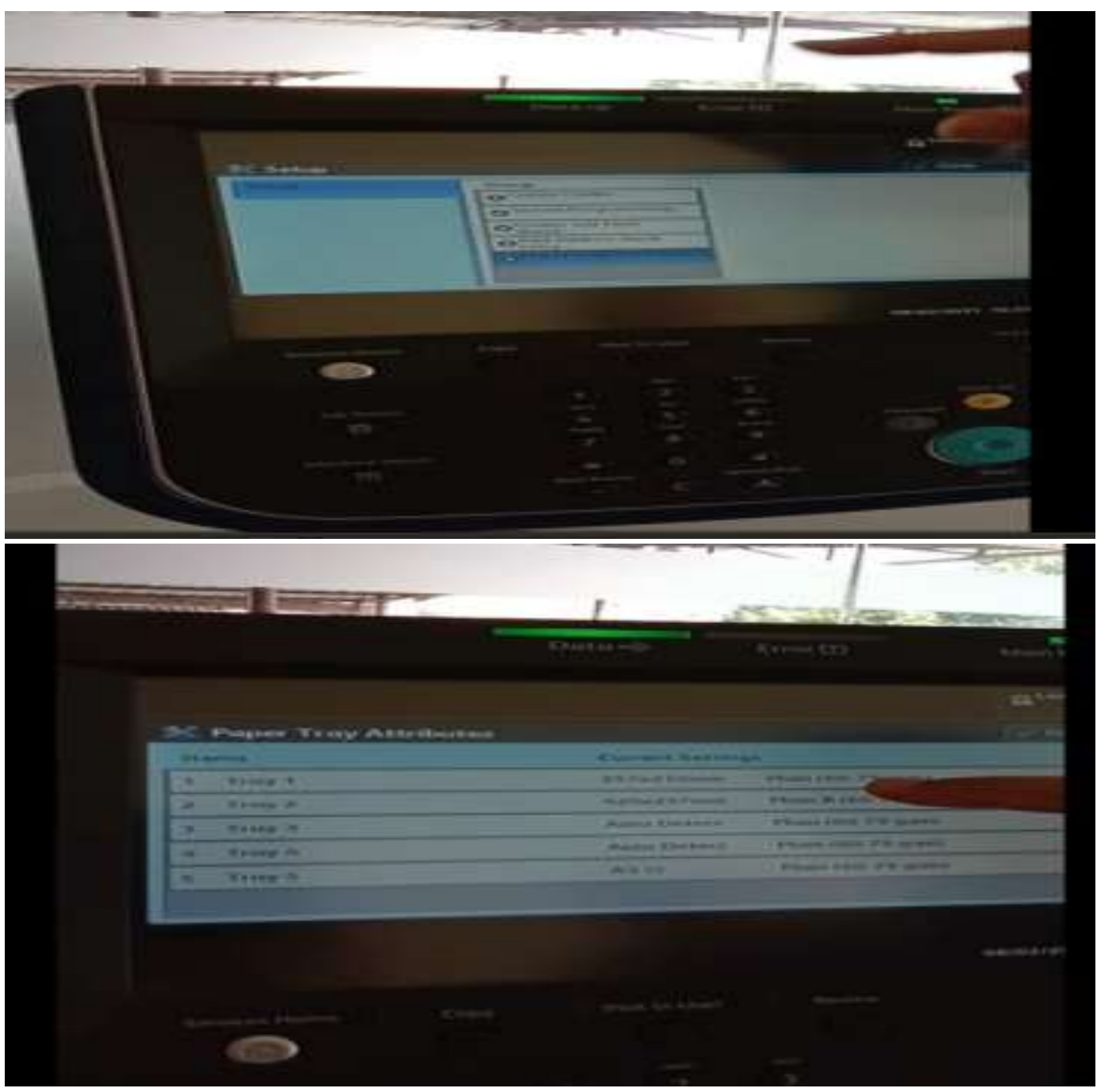

Gambar 8. Set Up : Paper Atributes Untuk Mengatur Tray Kertas 
Selanjutnya siswa mencoba diberi tugas mandiri untuk mencetak menggunakan mesin digital printing. Hal ini digunakan untuk mendapatkan respon peserta serta evaluasi dari kegiatan yang telah dilakukan. Mulai dari cara mengidupkan mesin, PC/computer, cara menggunakan aplikasi Fiery 1, mengatur layar monitor mesin, sampai ditahap akhir mencetak brosur di mesin digital printing. Berikut beberapa tahapan dan dokumentasi dari hasil cetakan pelaksanaan tugas mandiri siswa.

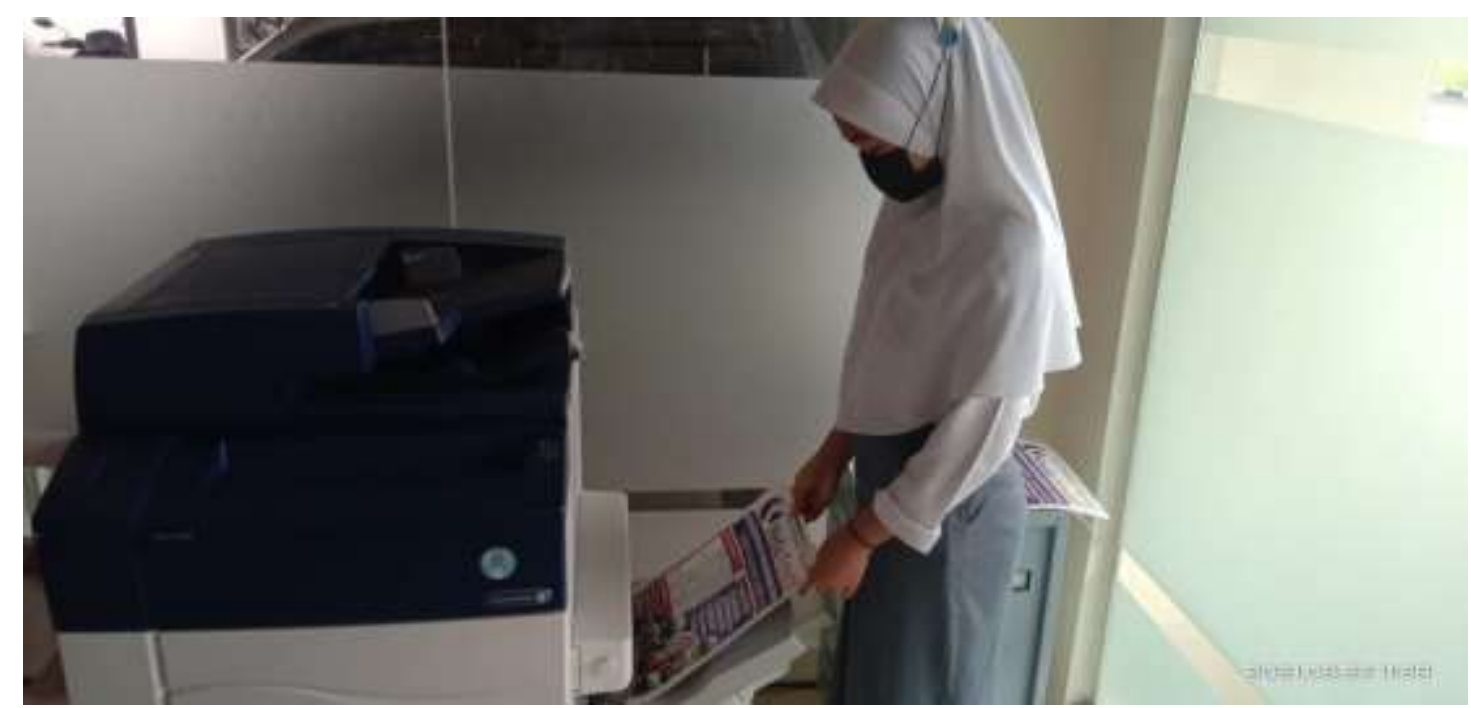

Gambar 9 . Siswa secara mandiri mencetak menggunakan mesin digital printing

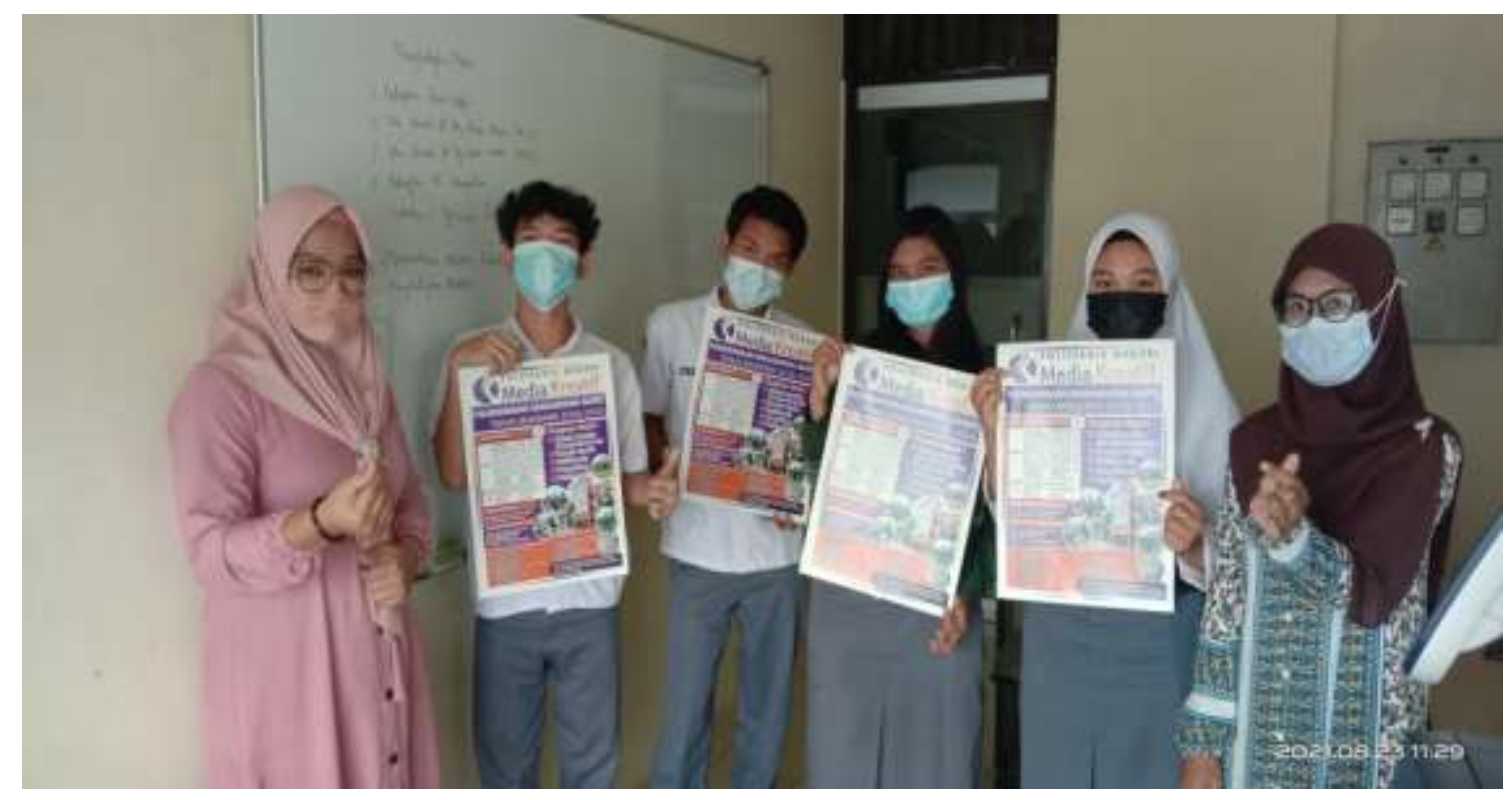

Gambar 10. Hasil Cetakan Siswa 


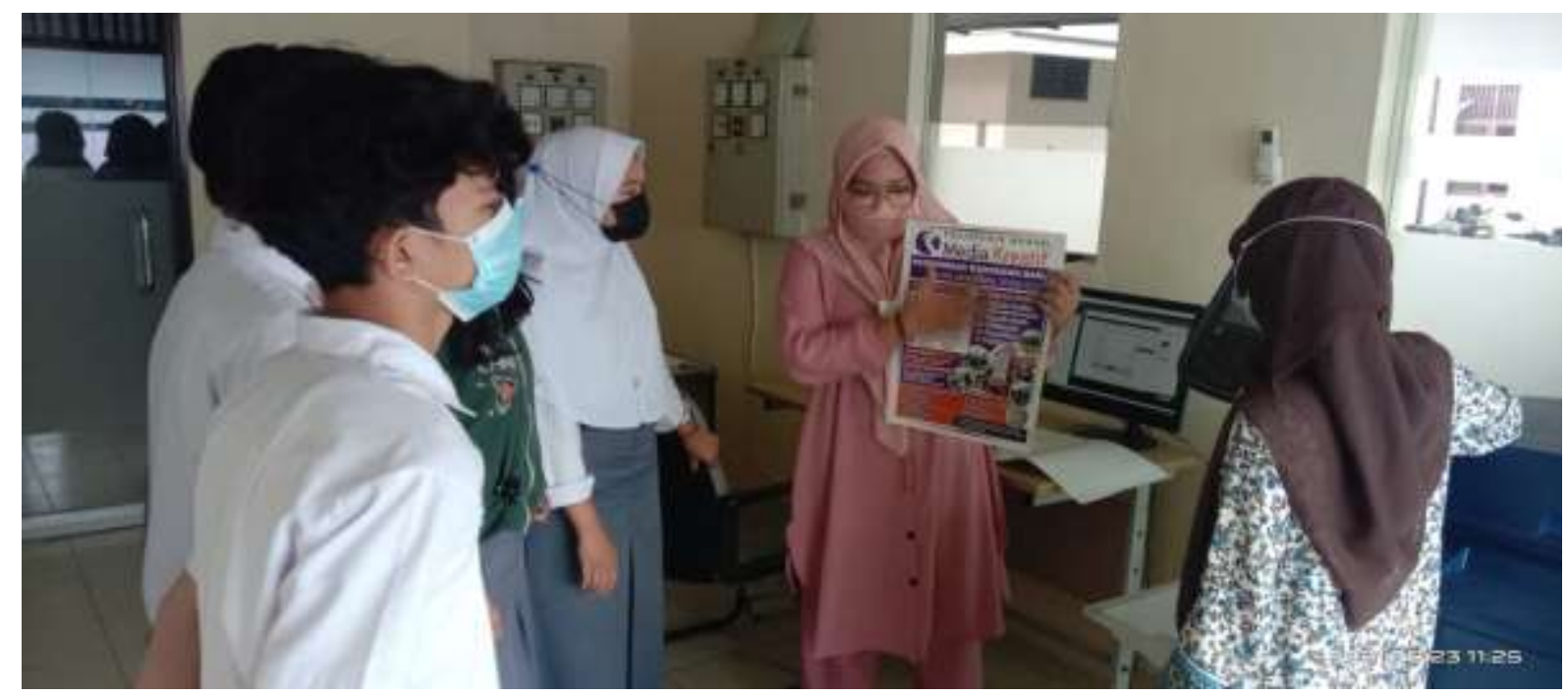

Gambar 11. Tim Pengabdi Menjelaskan Kekurangan dari Hasil Cetakan

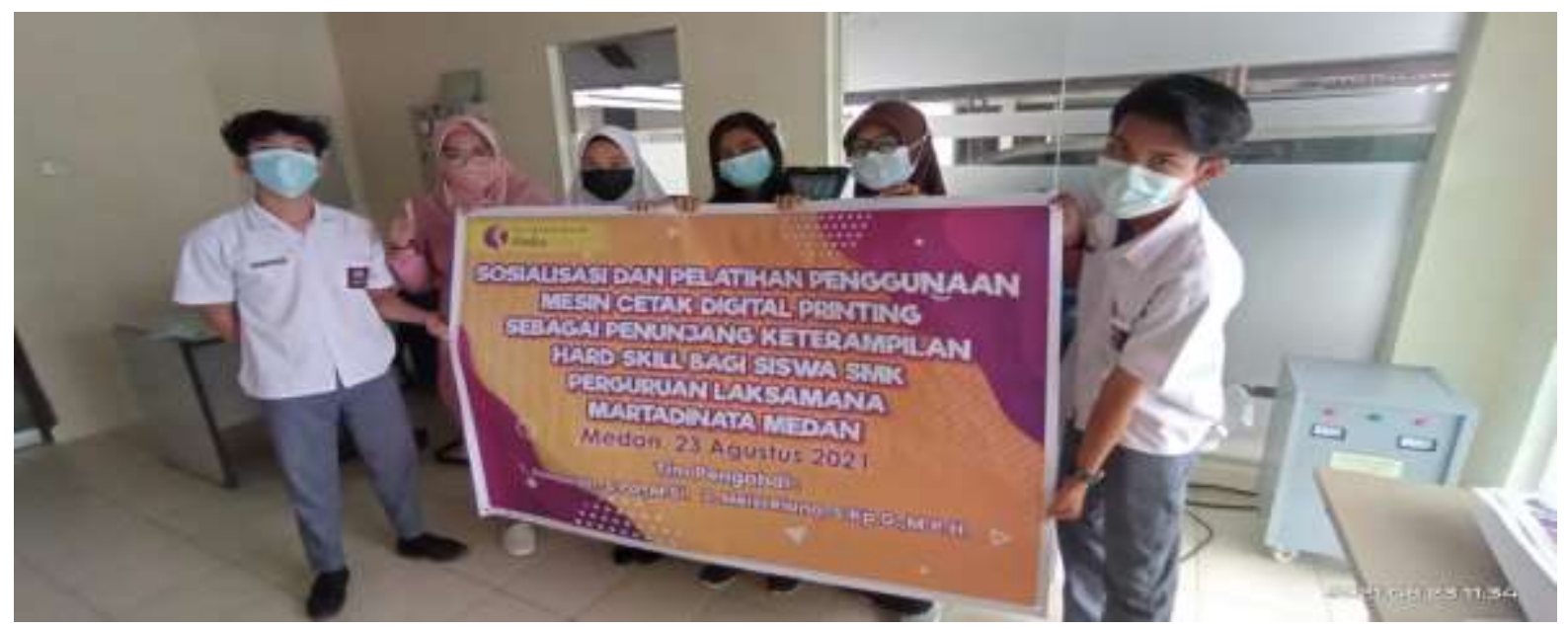

Gambar 12. Tim Pengabdi dan Siswa yang di Latih

Hasil dari kegiatan ini secara umum ialah bagaimana menstimulasi siswa belajar agar dapat memasuki jalur ekonomi produktif. Solusi utamanya melaksanakan pelatihan hardskill dalam bentuk keterampilan menggunakan mesin cetak digital printing di industri kreatif, yang dalam kegiatan ini difokuskan pada cetak brosur dan diproduksi dengan teknik cetak digital (Moerdisuroso et al., 2019)

\section{SIMPULAN DAN SARAN}

\section{SIMPULAN}

Dari seluruh rangkaian kegiatan dalam program pengabdian kepada masyarakat ini,dapat ditarik beberapa kesimpulan sebagai berikut: kegiatan pelatihan menggunakan mesin digital printing tersebut telah terlaksana sesuai dengan target yang diinginkan. Peserta pelatihan mendapatkan keterampilan, ilmu serta wawasan tentang mesin cetak digital printing; siswa/siswi dapat mengembangkan keterampilan hardskill; selama pelatihan menunjukan adanya peningkatan pemahaman dan ketrampilan dari beberapa peserta dalam mengoperasikan mesin digital printing; berdasarkan evaluasi melalui pelatihan mandiri yang telah diberikan, maka dapat diperoleh kesimpulan, bahwa peserta 
memahami cara mencetak brosur dengan hasil yang presisi menggunakan mesin digital printing.

\section{SARAN}

1. Perlu dilaksanakan kegiatan pelatihan mencetak selain brosur menggunakan mesin digital printing.

2. Baiknya dibuat pelatihan pada ekstrakurikuler di sekolah-sekolah dalam hal menggunakan mesin digital printing ini.

3. Perlu dilaksanakan pelatihan mendesain sebelum mencetak brosur menggunakan mesin digital printing.

4. Program ini dapat terus berlanjut sehingga siswa-siswi mempunyai bekal untuk berwirausaha digital printing setelah tamat dari sekolah.

\section{UCAPAN TERIMA KASIH}

Terima kasih kepada Politeknik Negeri Media Kreatif PSDKU Medan yang telah memfasilitasi Tim Pengabdi untuk menggunakan laboratorium Digital Printing.

Terimaksih juga kepada SMK Perguruan Laksamana Martadinata Medan yang telah memberikan kesempatan Tim Pengabdi untuk melatih siswa-siswi berharap menambah pengetahuan dan keterampilan hardskill peserta.

\section{DAFTAR RUJUKAN}

Dameria, Anne. 2003. Digital Workflow Dalam Industri Grafika. Jakarta. Link And Match Graphic.

Dameria, Anne. 2009. Digital Printing Handbook. Jakarta. Link And Match Graphic.

Ditto, A. (2017). Pelatihan Ragam Hias Minangkabau Melalui Teknik Cetak Dengan Digital Imaging Sebagai Apresiasi Seni Budaya Lokal. Jurnal Batoboh, 2(2).

Guntoro, G., Lisnawita, L., \& Sadar, M. (2019). Pelatihan Internet Sehat Dan Aman Bagi Siswa Smk Masmur Pekanbaru. Jurnal Pengabdian Pada Masyarakat, 4(2), 223230. Https://Doi.Org/10.30653/002.201942.105

Margomo, K. (2018). Formulasi Strategi Bersaing Perusahaan Digital Printing. Jurnal Agora, 6(2).

Moerdisuroso, I., Prayitno, E. H., \& Kherid, Z. (2019). Pelatihan Merancang Grafis Di TShirt Dengan Teknik Digital. Ikraith-Abdimas, 2(3), 151-160.

Petro, S., \& Swatan, K. H. (2019). Pelatihan Microsoft Excel Sebagai Penunjang Ketrampilan Hard Skill Bagi Siswa Pada Smk Ypsei Palangka Raya. Jurnal Abdimas Bsi: Jurnal Pengabdian Kepada Masyarakat, 2(2), 280-286. Https://Doi.Org/10.31294/Jabdimas.V2i2.6011

Saharja, K. (2020). Efektifitas Digital Printing (Pencetakan Digital) Dalam Menghasilkan Produk Cetak Dan Pengaruhnya Terhadap Konsumen. Binawakya, 14(11), 34293438. Https://Doi.Org/Https://Doi.Org/10.33758/Mbi.V14i11.617 
Septiara, V., Ambarwati, A., \& Nugroho, A. (2020). Rancang Bangun Sistem Informasi Manajemen Pemeliharaan Mesin Percetakan Digital Printing Berbasis Desktopmenggunakan Vb.Net (Studi Kasus: Cv. Wujud Unggul). Sistem Informasi.

Wahid, A., \& Luhriyani, S. (2015). Pelatihan Dan Penerapan E-Learning Dan MLearning Berbasis Moodle Bagi Guru Siswa Smk Persada Dan Bajiminasa Makassar. Jurnal Inovasi Dan Teknologi Pembelajaran, 1(2), 102-107.

Wasesa, A. J. A., \& Jumali, M. A. (2020). Analisa Produktifitas Mesin Digital Printing "Sakurai Oliver458-Eii" Diperusahaan Percetakan Sidoarjo. Jurnal Teknik Waktu, 18(1), 46-51.

Witari, N. N. S., \& Suryana, J. (2020). Pelatihan Cetak Stensil Untuk Mengasah Kreativitas Remaja Di Panti Asuhan/Lksa Widhya Asih, Singaraja. Proceeding Senadimas Undiksha 2020, 2015, 1352-1360.

Yuniarti, Y., \& Mauliana, S. (2012). Strategi Pemasaran Produk Digital Printing Pada Cv. Fnb Digital Jambi. Jurnal Mnajemen Fakultas Ekonomi Universitas Jambi, 1(1), 1689-1699. 